\title{
Students' satisfaction with library services and facilities at three regional center libraries of the Open University of Sri Lanka
}

\author{
P.K.M. Kaushamalika ${ }^{1}$, W.R.W.M.A.U. Weerakoon ${ }^{2}$
}

\begin{abstract}
The study was carried out to examine the user satisfaction of library facilities, services, and resources of three regional center libraries; Kandy (KRC), Matara (MRC) and Anuradhapura (ARC) of the Open University of Sri Lanka, which functions as an open and distance learning (ODL) education institute. Data was collected using a survey questionnaire, from a sample of 350 library users dispersed among the three centers. The study found that the users were satisfied with the physical facilities in the libraries but they were unsatisfied with the library collection and computer facilities provided by the libraries. Findings of the study can be used to reinforce the services with which the users were satisfied, focus on services that need more improvement according to user concerns, and to take steps for resolution of identified problems to gain users' satisfaction.
\end{abstract}

Keywords: Open and Distance Learning, Academic Libraries, User Satisfaction, Library Physical Environment, Library Collection

1 Senior Assistant Librarian, Matara Regional Centre, Open University of Sri Lanka. Email: pkkau@ou.ac.lk, (D) http://orcid/0002-2398-5573

2 Senior Assistant Librarian, Kandy Regional Centre, Open University of Sri Lanka. Email: auwee@ou.ac.lk 


\section{Introduction}

Every library attempts to provide a quality service to meet the information needs of its users. The character and extent of such services will vary with the kind of library or information centers and the type of users. The effectiveness of any information service can be measured by the degree to which its resources are utilized and the extent to which the services meet the information needs of its users. User satisfaction refers to whether users get the desired information resources, facilities, and services at the library and how users judge the services of a library.

Purpose of a library is beaten if its users are not satisfied with the resources and services it provides. Therefore, the information services are to be developed not only to meet user needs and to improve present services but also to anticipate users' needs in the future. The library management must have a thorough knowledge of the user's needs through periodical assessments.

As mentioned earlier the user category is a significant factor in designing services. The current study focuses on Open Distant Learners (ODL) engaged in tertiary education at the Open University of Sri Lanka (OUSL).

In the late 1970s, it was realized that in spite of all expansion and development of education in modern Sri Lanka, there remained a great reservoir of people who had not availed themselves of the opportunity for further education. There was a need to offer the public a second opportunity in education (Ryhana, 2010). As a solution, The Open University of Sri Lanka was established in June 1980, by a group of educationists supported wholeheartedly by the political leadership of that era.

The Open University of Sri Lanka (OUSL) is the premier Open and Distance learning institution in Sri Lanka where students can pursue their studies through Open and Distance Learning (ODL) methodologies. Due to the nature of its teaching methodology and infrastructure, the OUSL can serve a large student population spread throughout the country. Currently, more than 35,000 students are studying at the OUSL, who are being served by Eight Regional Centers and Eighteen Study Centers located around the country 
(OUSL statistics, 2015). The central campus and one regional center are situated in Colombo: the capital of Sri Lanka. The other regional centers are situated in Kandy, Matara, Jaffna, Anuradhapura, Kurunegala, Batticaloa, and Badulla; the main cities of the country. These centers were established and developed to provide learner support services to ODL students in the local communities.

The OUSL library system is different from a conventional library system in its scope of services and physical distribution. Though the library was set up initially to support the academic staff to prepare and compile distance learning materials and for their academic research, the role of the library has gradually changed, and now it is the main learning support service provider for the distance learners. The library promotes open learning culture through specialized facilities provided in the library such as access to; question papers, course material collection, audiovisual learning support collection, virtual library, remote library services, and cluster learning facilities. It also provides facilities for knowledge exchange and scholarly communication through discussion room facility in the library. Moreover, for serious learners, the library provides facilities for individual and more absorbed learning.

The extent and quality of student support services, including library services are considered as a vital component in ODL education. Today there is an increased recognition of the need for library resources and services at locations other than main campuses in an ODL system. The OUSL library provides its services to users through the main library located in Nawala Main Campus and eight Regional Centers located around the country. Out of these, the libraries at Kandy RC, Matara RC and Anuradhapura RC are the widely used libraries. At the same time these three centers cater to a large proportion (30\%) of the OUSL student count (OUSL statistics, 2015). Therefore, it is important to investigate users' level of satisfaction with the services provided by these libraries in order to further strengthen the areas of services in which the users are satisfied and, to discover weak areas, which could be improved. This study is the first of its kind investigating users' level of satisfaction with the services of these three libraries. The findings of the study will be useful in order to succeed in the ODL education provided 
by these three centers. Further the findings can be used by library professionals in Sri Lanka and other developing countries in investing improvement in their library services.

\section{Research Objectives}

The study aimed at assessing the following behavior pattern of regional library users to;

i. identify the frequency of visiting regional center libraries

ii. find out the purposes of visiting regional center libraries

iii. determine the level of satisfaction of users towards library resources, service, and facilities

iv. identify areas that needs to be improved

\section{Literature Review}

It is common in the developed world for libraries to conduct user satisfaction surveys to improve the level and quality of services offered to users (Mairaj and Naseer, 2013). These surveys help in evaluating the strengths and weaknesses of libraries and provide an opportunity for library managers to enhance user satisfaction. Despite the numerous advantages, deep analysis of users' perceptions and satisfaction about library services have largely been ignored by researchers and practitioners of library and information science in developing countries (Mairaj and Naseer , 2013). Some recent studies recorded in some developing countries including Sri Lanka are discussed under the literature review section.

Based on a study on student satisfaction with library services in Trincomalee campus in Sri Lanka, Vijeyaluxmy (2015) suggests that it is inevitable for an academic library to provide richer information sources to their users to meet information needs in the present environment in which information explosion and customer care are the major challenges. In this context, library management needs to conduct user studies annually to have feedback from users on how well the library is meeting their information needs. The results of the survey should be conveyed to the library administrative body for the necessary step towards library development and user satisfaction. 
Nawarathne and Singh (2013) assessed the perceived level of satisfaction of its users towards services provided by the Sabaragamuwa University library in Sri Lanka. The study identified that library staff is quite helpful and able to instill confidence in library users as they use the library for various purposes. Authors have concluded that whatever the facilities and equipment available in the event, if the staff is not geared and motivated to provide quality services, the entire effort would not be fertile.

A case study carried out by Veena and Kotari (2016) in the SDM college library, Ujire, India revealed that the majority of students were satisfied with the textbook collection, circulation services, and library space. Further, the authors recommended that the library should organize user orientation or awareness programs at the commencement of every educational session. This will support learners and research scholars to effective use of library resources.

Ababio et al., (2012), investigated the students' satisfaction levels with individual service components of Kumasi Polytechnic Library in Ghana and its effect on their rating for overall service quality. The fitted ordinal logic model suggests that student rating for overall service quality of library decreases when they are less satisfied with the individual service components such as relevant materials at the library, reliability of the internet facilities, service queue, user instructions and the attitude of the supporting staff. Among these service components, current and relevant materials were found to be the most significant library service component that influences students' ratings for overall service quality. Also, course materials, computers as well as internet facilities were the three main library service segments that students requested for necessary improvement.

Larson and Owusu-acheaw (2012) studied undergraduate students' satisfaction with library services in a faculty library in the University of Education, Ghana. Results of the study revealed that though students were satisfied with the present services, there are new areas to be looked in to. The study also provides evidence for the management to allocate sufficient and regular budget for the library. 
A handful of studies have been carried out to study various aspects of the OUSL library system, but none of them have focused on user satisfaction regarding individual service components and facilities in the regional center libraries. The current findings are presented as an extension of the study reported by Kaushamalika, Arachchige, and Weerakoon (2018) which focused on user perception.

\section{Methodology}

To accomplish the above objectives of the study, a survey method was used with a well- structured questionnaire to collect data from the users of three regional center libraries of the OUSL. These three centers were selected from eight centers of the OUSL, considering their homogeneity of services and similarity of administration and facilities.

The total population of this study was 1550 registered active members dispersed among the 3 libraries. As the population was too large for the study a sample was selected on stratified random basis. Thus representing $20 \%$ of the target population, 100 and 200 students were selected from MRC and KRC respectively. However, the whole population at ARC was 50 and taking $20 \%$ of 50 would be insufficient to represent the population for generalization. Therefore, the whole population (50) of ARC was selected for this study. A sample of 350 respondents from undergraduate students in three study levels (levels 3, 4 and 5) of all four faculties were selected randomly using the non-proportionate quota sampling technique.

Apart from the student sample, Assistant Librarians who in-charge of the three RCs were interviewed to find data related to the facilities and services available at RC libraries.

The questionnaire which divided into five main sections was used as the main research instrument to gather data. A total of 350 questionnaires were distributed and 328 questionnaires were returned with a response rate of 96\%. The center wise response rate was $100 \%$ in ARC and MRC whereas it was $89 \%$ in KRC. The study explores fourteen major areas of library usage and services through the questionnaire. 
The Likert scale method was adopted to know user's satisfaction of library facilities, services and resources in their respective regional centre libraries.

\section{Results and Discussion}

Demographic characteristics of respondents

Demographic factors can influence the use of the library, informationseeking behavior, and needs of information. Tables $1 \& 2$ show the demographic data of respondents.

Table 1. Age Differences

\begin{tabular}{lrrrrr}
\hline & ARC & MRC & KRC & Total & $\%$ \\
\hline $25>$ & 10 & 44 & 113 & 167 & 50.9 \\
$26-36$ & 30 & 52 & 61 & 143 & 43.6 \\
37 or above & 10 & 4 & 4 & 18 & 5.5 \\
\hline \multicolumn{1}{r}{ Total } & $\mathbf{5 0}$ & $\mathbf{1 0 0}$ & $\mathbf{1 7 8}$ & $\mathbf{3 2 8}$ & $\mathbf{1 0 0}$ \\
\hline
\end{tabular}

Source: Survey data

The majority of respondents of the three centers taken collectively belonged to the age category of 25 or below (50.9\%) while $43.6 \%$ were between $26-36$ years and a minor portion of $5.5 \%$ were above 37 years.

Table 2. Gender Analysis

\begin{tabular}{lrrrrr} 
& ARC & \multicolumn{1}{l}{ MRC } & \multicolumn{1}{l}{ KRC } & \multicolumn{1}{l}{ Total } & $\%$ \\
\hline Male & 15 & 36 & 68 & 119 & 36.3 \\
Female & 35 & 64 & 110 & 209 & 63.7 \\
\hline Total & 50 & 100 & 178 & 328 & 100 \\
\hline
\end{tabular}

Source: Survey data

According to gender analysis, the majority of users were females (63.7\%). In the track of marital status, single (79\%) were higher than married persons (21\%). Users were found to be employed in different sectors. Employed users $(50.6 \%)$ were slightly higher than unemployed users $(49.4 \%)$. This is 
understandable as OUSL was initially established to facilitate life-long learning of working adults.

Frequency of library visits by users

According to Table 3, as a whole $21.65 \%$ of users visit the RC libraries daily while $20.35 \%$ of users visit twice a week. It is interesting to note that despite being distance learners a significant proportion of users $(60.81 \%)$ visit the library at least once in a week. Specially, this indicates the importance of the library as a learner support service for distance learners.

Table 3. Frequency of library visits by users

\begin{tabular}{lrrrrr}
\hline & ARC & MRC & KRC & Total & $\%$ \\
\hline Daily & 10 & 9 & 52 & 71 & 21.65 \\
Twice a week & 10 & 19 & 41 & 70 & 20.35 \\
Once a week & 10 & 27 & 35 & 72 & 21.95 \\
Twice a month & 10 & 18 & 8 & 36 & 10.97 \\
Once a month & 5 & 11 & 13 & 29 & 8.84 \\
Occasionally & 5 & 16 & 29 & 50 & 15.24 \\
\hline Total & $\mathbf{5 0}$ & $\mathbf{1 0 0}$ & $\mathbf{1 7 8}$ & $\mathbf{3 2 8}$ & $\mathbf{1 0 0}$ \\
\hline
\end{tabular}

Source: Survey data

It is also important to consider $8.84 \%$ of users who visit the library monthly when designing and developing services and facilities. For example, the administration can consider extending the lending period of library material from 2 weeks to three weeks as requested by some users in section $\mathrm{E}$ of the survey questionnaire.

Purpose of using the library of RCs:

Respondents were given the choice to mark multiple answers and they have given various reasons for visiting the library. The frequency of each response was calculated. A majority of respondents $(59.45 \%)$ use the library to refer books in the collection while $50.30 \%$ of users had visited to search for information from the collection. Furthermore, $48.17 \%$ use the library to borrow and return books and, $41.77 \%$ to prepare assignments. Moreover, 
$39.94 \%$ visit the library to read notes. Those who visit the library to study with friends were $37.50 \%$ and a proportion of $32.01 \%$ use the library for leisure reading. A fewer number $(18.60 \%)$ visit the library to refer to journals and periodicals. Only a few users use the library to surf the internet (7\%) as the RC libraries are unable to install adequate computer and internet facilities.

Results show that the library space is very important for distance learners for various learning activities such as reading notes, studying with friends, relax reading and preparing assignments $(41.77 \%)$. The next important purpose of visiting the library was found to be: to use the library collection (books, periodicals, online material) directly. The frequency of this response was $85.37 \%$. The $48 \%$ who are involved in the circulation of library material can be identified as established users who are familiar with the collection while the $50 \%$ who visit in search of information may include the potential users whom the library should try to entice.

The level of satisfaction of users towards library resources, service, and facilities

\section{Adequacy of the library collection}

Studies have shown that an adequate collection of library material: in both print and online formats, is the key to provision of information and it is closely associated with the users' perceptions of library effectiveness.

A reasonable proportion of users $(40.29 \%)$ were not satisfied with the collection coverage of the three regional center libraries while $29.71 \%$ of users were satisfied and $4.29 \%$ of users very much satisfied. Only $7.71 \%$ of users were not at all satisfied with the collection. A small proportion of $4 \%$ had no idea about the collection. See figure 1. 


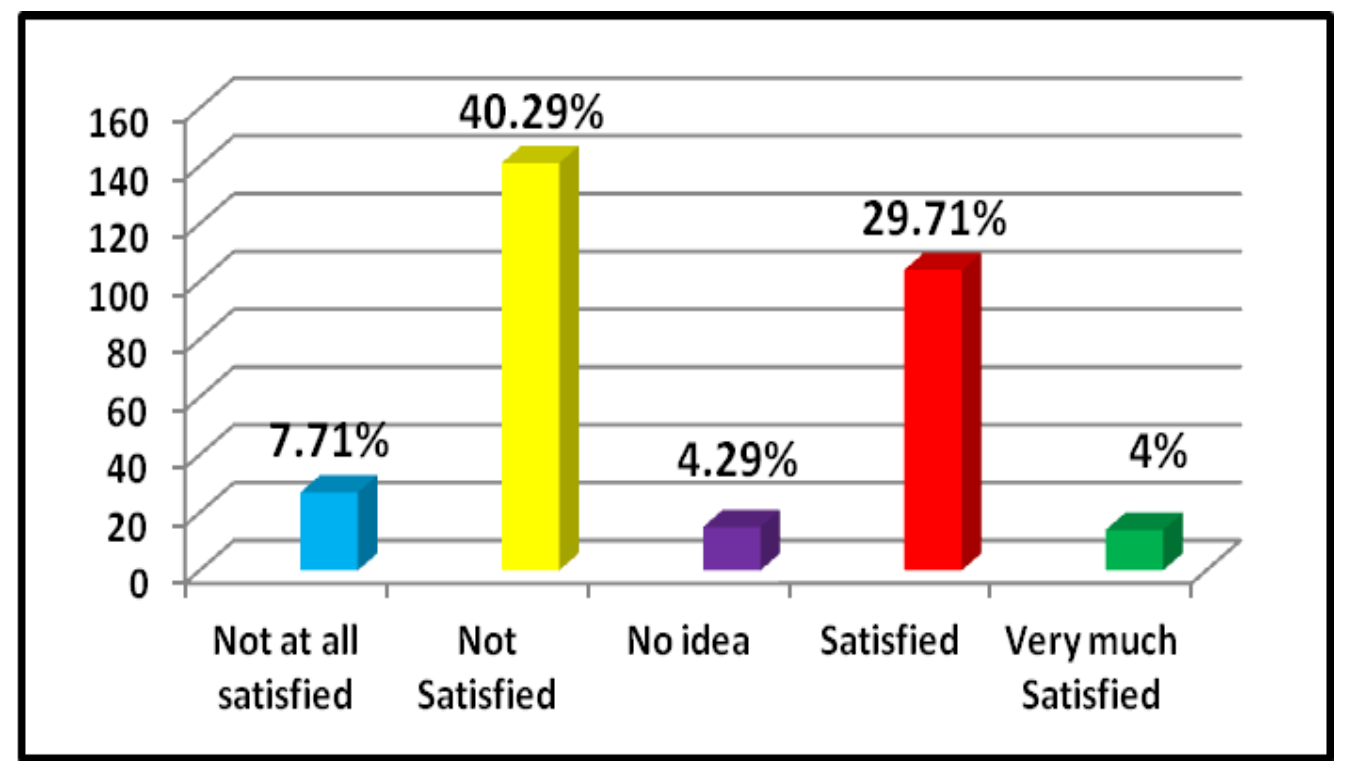

Figure 1. Satisfaction of the library collection

Responses given by users helps to identify the areas to be developed to build a satisfactory collection to fulfill user needs. Few users (36\%) have stressed the need for multiple copies of books. An approximately similar proportion of responses (30.86\% and 30.57\%) shows that the 'collection is not comprehensive enough' and 'the non-availability of new editions' respectively. Also, $18.57 \%$ of users revealed the need to add reference materials to the existing collection. A reasonable proportion (24\%) claimed that IT facilities are not enough.

According to the comments made in section $\mathrm{E}$ of the survey questionnaire (comments and suggestions), $42 \%$ of the respondents believed that the resource collection should be increased. Other than developing the textbook collection, this includes incorporation of audio /visual facilities (5\%) and Copies of past question papers (4\%). Stressing the importance of modern ICT, $15 \%$ have suggested the need for fast internet connectivity and Wi-Fi access in the library. The current study identifies that more than $85 \%$ of users visit the library to use the collection directly. Therefore, it is important to fill the gaps in the collection. 


\section{Organization of the library collection}

Libraries are reputed for providing material in an organized manner for user's convenience and librarians use various tools for this purpose. Shelf arrangement, book labels, instructions, notices, and displays should assist and guide the information seeking process. The expressions used by different participants regarding the organization of the collection show that a majority of $189(54 \%)$ users were satisfied with the shelf arrangement of the libraries while $35(10 \%)$ were very much satisfied. However, 26 (7.43\%) students were not satisfied with shelf arrangement while $19(5.43 \%)$ were not at all satisfied. A small proportion of 6 students $(1.71 \%)$ had no idea about this factor. These findings are clearly shown in Figure 2.

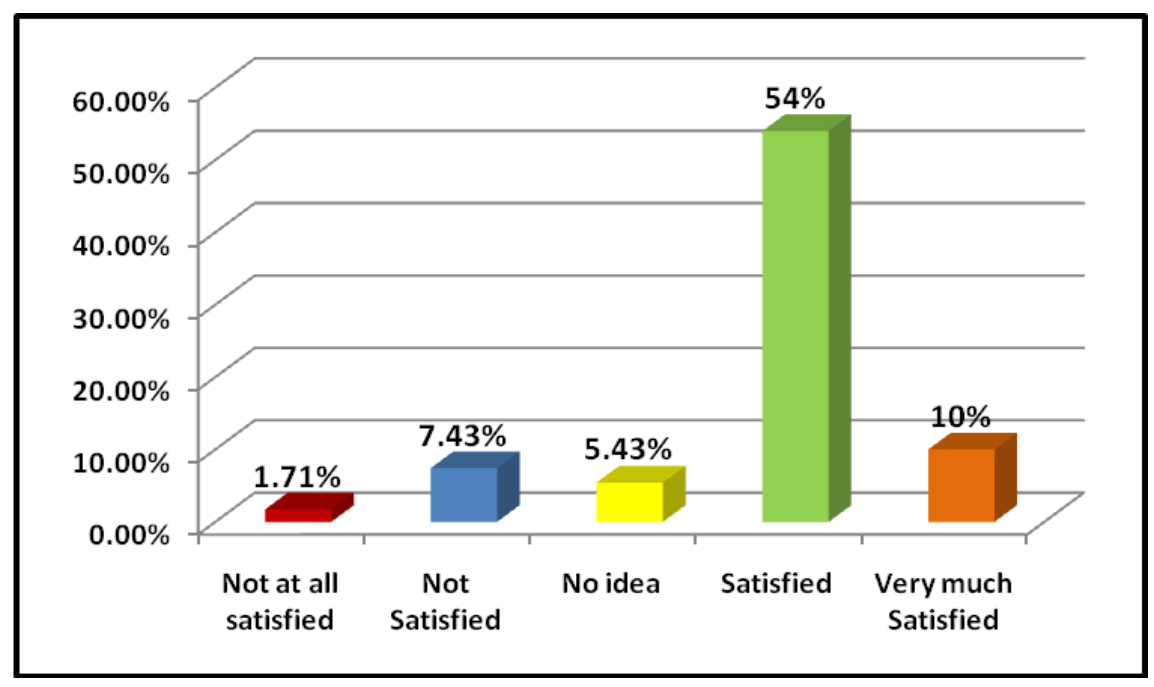

Figure 2. Satisfaction of shelf arrangement in the libraries

\section{Lighting arrangement}

Libraries should be designed in such a manner that proper light conditions are provided for users because lighting influences certain health aspects such as vision and also user comfort, productivity, and perception of space. Figure 3 simply displays the satisfaction levels of the lighting of the RCs. Most of the respondents $(63.71 \%)$ found that existing lighting arrangements are satisfactory while (16\%) found that it is highly satisfactory. Some respondents thought that the lighting was not satisfactory $(5.14 \%)$ and must be improved further. 


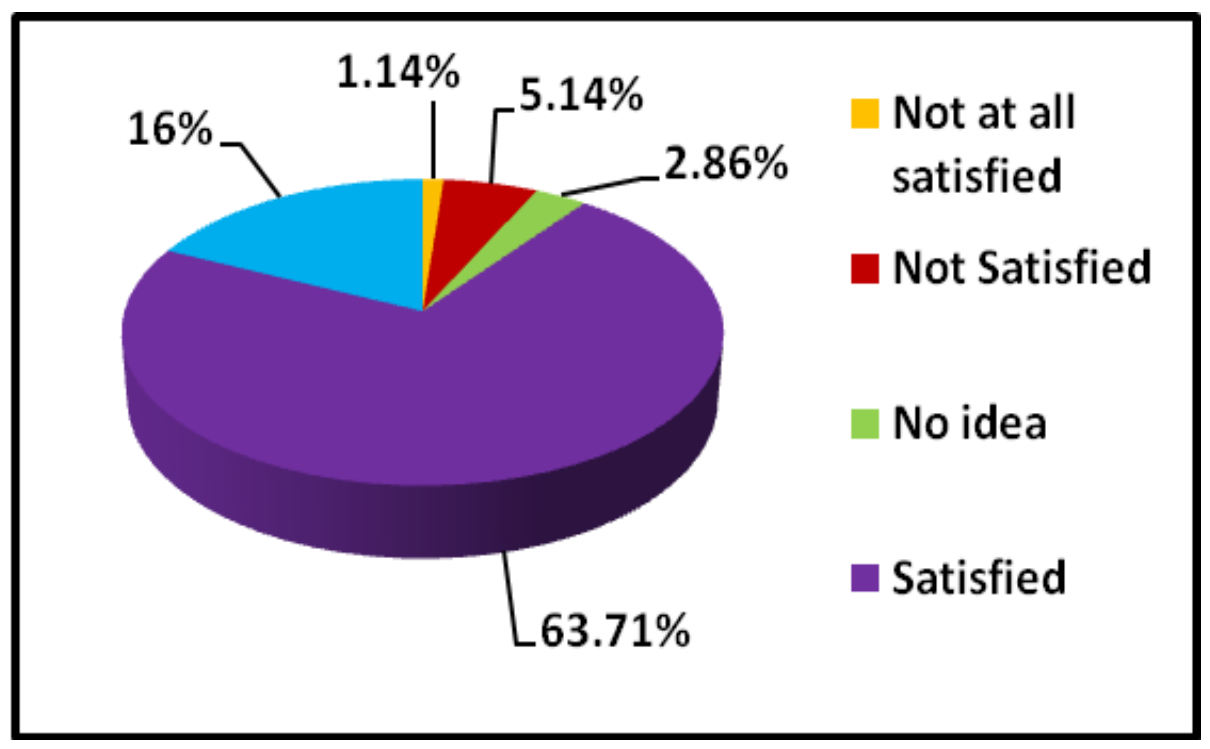

Figure 3. Satisfaction of lighting arrangement of the libraries

The attitude of library staff perceived by users

Attitude always counts to determine the impression of a person. Library staff should be humble, well behaved and cooperative while serving. The majority of respondents $(48.57 \%)$ were satisfied with the attitude of library staff whereas $30.57 \%$ of respondents were very much satisfied with the cooperation and behavior of library staff and found them 'friendly' and 'helpful' while serving users. Some users $(4.86 \%)$ were not aware of the factor and stated to have no idea. Unfortunately, 3.43\% and $2.57 \%$ of users were not satisfied or not at all satisfied with the behavior of staff.

\section{Library hours}

In ODL mode of learning users should be provided with opportunities to study at their own convenience. Regional center libraries remain open from 8:15 a.m. to 4:15 p.m. through 7 days of the week. These libraries are closed only on religious holidays, other public holidays and Special University Holidays. On average the libraries are kept open for 330 days per year.

A majority of users (67\%) were satisfied with opening hours with $48 \%$ users being satisfied and $19.14 \%$ users very much satisfied. About $15 \%$ of users were not pleased with the available times with $12 \%$ being not satisfied and 
$2.57 \%$ not at all satisfied. $2.57 \%$ of users had no idea about the adequacy of the opening hours of the library. According to comments made in section $\mathrm{E}$ of the survey questionnaire, it was found that users (4\%) prefer to have extended library opening hours during examination periods. See figure 4.

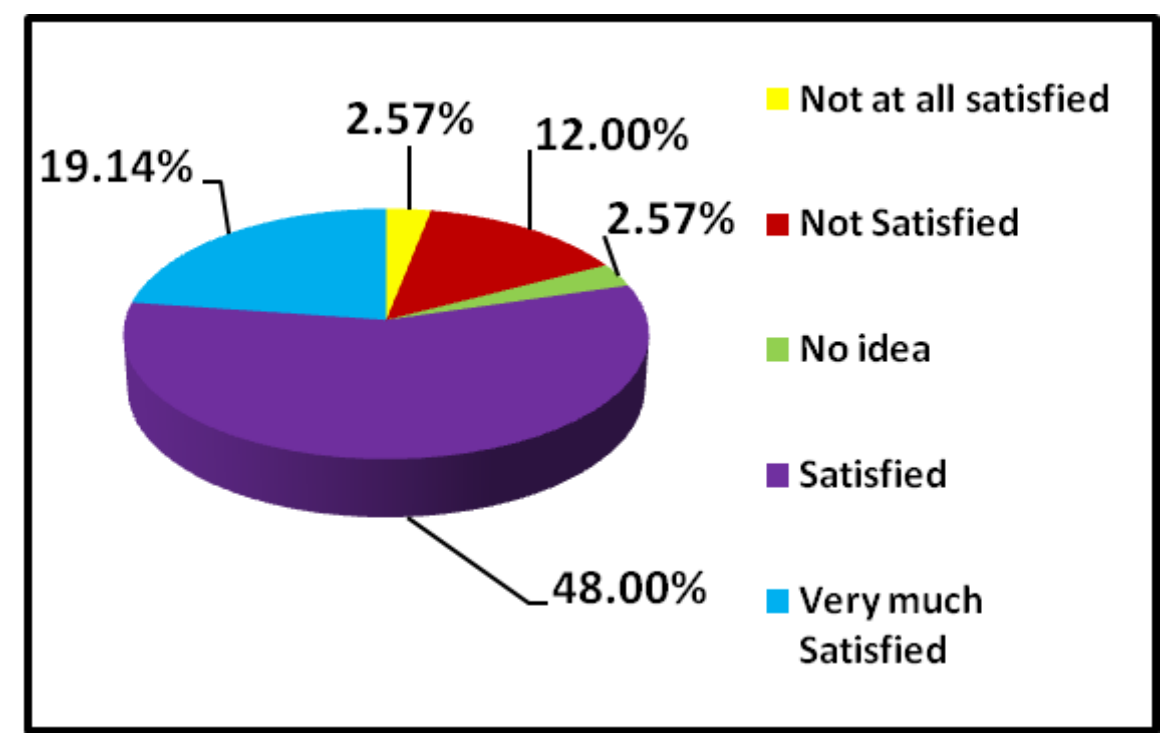

Figure 4. Satisfaction of the opening hours of the libraries

\section{Library space and seating capacity}

A library must have sufficient space to accommodate different users with different needs. For example individual study rooms, group study rooms, spaces for laptop users etc. with the primary aim of providing comfortable working conditions for users. In addition a library must possess adequate space for housing the collection such as books and journals, audio-visual materials and staff accommodation. All respondents showed their concern about library space.

A greater proportion of users acknowledged the seating capacities of the regional center libraries to be satisfied $(39.14 \%)$ or very much satisfied $(5.43 \%)$. However, $28.86 \%$ of users were not satisfied or not at all satisfied $(6.86 \%)$ with the seating space provided. A minute proportion $(3.14 \%)$ indicated 'no idea' about this. From responses gathered under section E, most respondents believed that although the space at present was adequate, it 
needed to be extended shortly. Figure 5 visually displays the satisfaction levels of the library space and seating capacity in RC libraries.

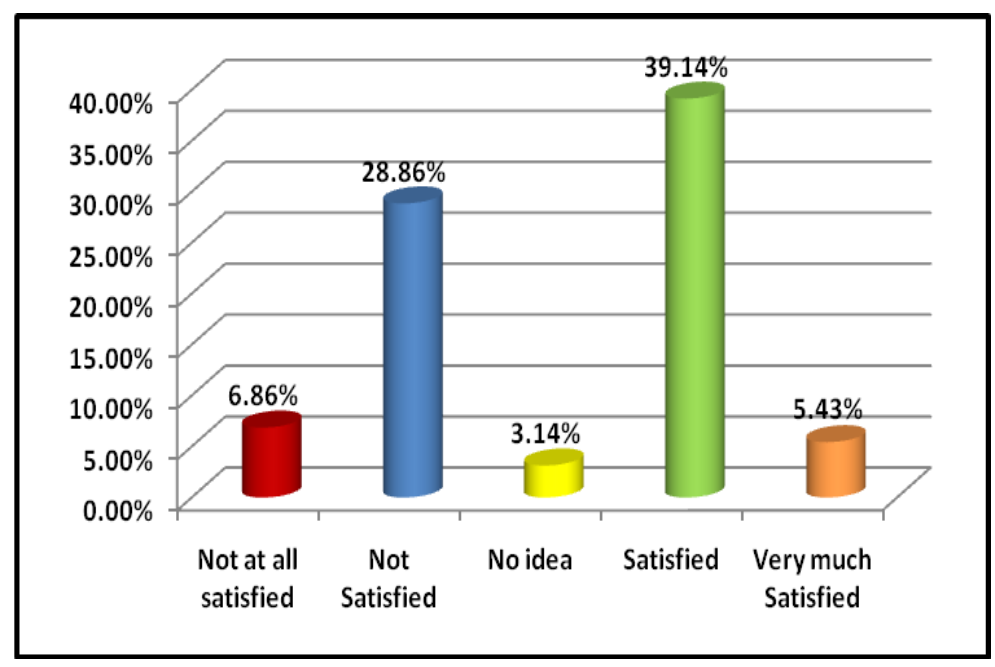

Figure 5: Satisfaction of seating capacity in the libraries

\section{Computer facilities}

As mentioned in earlier sections the regional center libraries are still unable to provide adequate computer facilities to users due to special, physical and financial issues. Regional centers KRC and MRC have provided both computer facilities and internet facilities to a certain extent but ARC library does not have the infrastructure facilities for the provision of internet access.

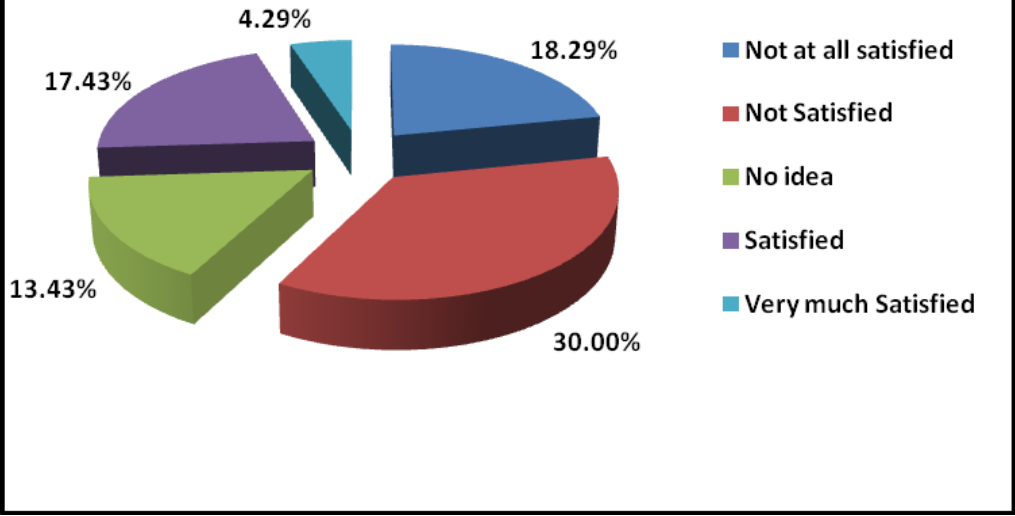

Figure 6. Satisfaction of computer facilities in the libraries 
Therefore, when taken as a whole $30 \%$ of users were not satisfied with the computer facilities provided at the library. Inevitably, $18.29 \%$ have stated that they were not at all satisfied. A reasonable number (17.43\%) were satisfied with computer facilities while a very few (4.29\%) users were very much satisfied. Some users $(13.43 \%)$ had no idea about this facility (See figure 6).

\section{Virtual resource center (VRC) facilities}

The objective of a VRC is to enable users to access online resources provided by the library via its web portal and other academic resources in the World Wide Web. Since all RC libraries have limited computer facilities within their premises, accessing these online/virtual resources on campus is hampered. However, users can access the library web page via mobile devices or remote access.

Among those who are aware of this facility, $14.86 \%$ were satisfied while $2.86 \%$ were very much satisfied. About $(22.86 \%)$ users had no idea about VRC facilities. Users who are unable to access VRC as desired, were either not satisfied (17.14\%) or not at all satisfied (10\%).

\section{Photocopy service}

Reprographic services in a library help to enhance the usage of its collection and prevent damage to and theft of library material. The latest trend is to take images of self-own mobile devices. However, libraries must provide adequate reprographic services to their users. All three regional center libraries have provided outsourced photocopy services for economical rates. The service providers have been renewed annually after considering their quality of the service. Most of the users were satisfied (46.86\%) or very much satisfied $(20.57 \%)$ with the photocopy service during the period of this study. However, $13.43 \%$ were not satisfied and $6 \%$ not at all satisfied. Few users $(4 \%)$ had no idea about the photocopy service of the RC libraries.

\section{Cleanliness}

A clean environment helps people to concentrate. A dirty library does not help anyone's study skills and can lead to worrisome health conditions. Therefore, maintaining the cleanliness in the library is very important to 
library users and others. Users in all three libraries were satisfied with cleanliness in the libraries $(60.29 \%)$ while $19.14 \%$ of respondents very much satisfied with this. A minor proportion was either not satisfied (2\%), had no idea $(2.57 \%)$ or not at all satisfied (3.14\%) with library cleanliness.

\section{Rules and regulations}

Libraries have established their rules for the purpose of securing library material, safety of users and to ensure that all users make the maximum benefit from its facilities. Library users are expected to comply with the rules and regulations of the university libraries and library staff instructions. More than half the users (56\%) were satisfied with the rules and regulations of the libraries while $19.14 \%$ of users were very much satisfied. A very minute proportion of users $(1.14 \%)$ were not at all satisfied with this factor while $4.57 \%$ of students were not satisfied and $4 \%$ of students had no idea about their preferences. (See figure 7)

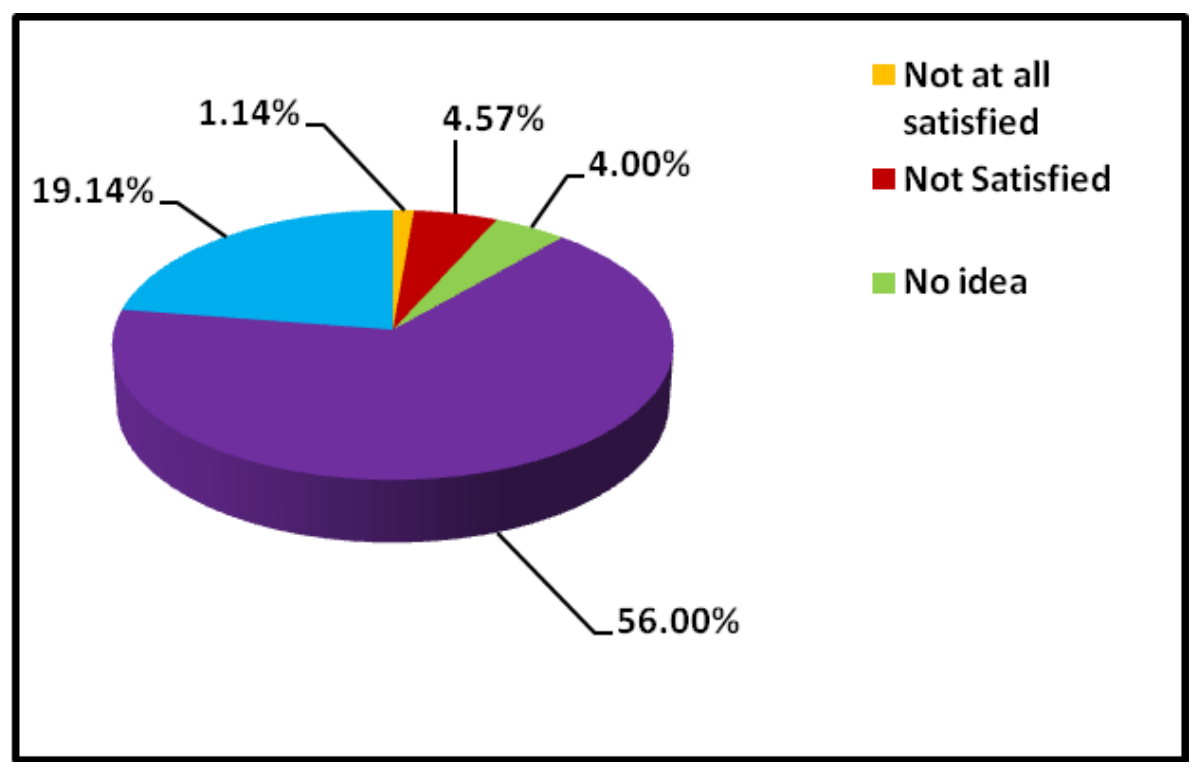

Figure 7. Satisfaction level of library policies

Security in the library

In this study the safety of patrons and staff is considered under security excluding security of library material. All three libraries have deployed security personnel to monitor and assist users at the baggage counter where 
they place their belongings and, at the main entrance of the library to monitor ingress and egress. The majority of $(48.86 \%)$ users were satisfied with security in the libraries while $28.29 \%$ of respondents were very much satisfied. A small portion (4.29\%) of users were not satisfied or not at all satisfied $(1.71 \%)$ with security in the library. Some of the users $(0.86 \%)$ had no idea about the security in the library.

Suggestions given by users for a more satisfactory service

The pivotal task of libraries is to meet the information needs of the users. Therefore, the opinions of users are always counted in improving the library services. In this study, under section $\mathrm{E}$ of the questionnaire, the participants were asked if they had any further suggestions for the overall improvement of the library. This question was asked to explore further areas in the users' minds that need to be addressed for improved library services, which in turn would enhance the level of satisfaction of users.

i. The most widely stated suggestion (42\%) was to increase the number of information resources including textbooks, reference resources, journals, course materials designed by the university, online resources and $\mathrm{CD}$ / DVDs with accompanying viewing facilities.

ii. Some respondents $(21 \%)$ had indicated that the Library needs to enhance its physical environment by providing more ventilation and enough seating capacity.

iii. The prevailing problems related to modern ICT use, including the inadequacy of computers, slowness of internet connection and unavailability of Wi-Fi in the regional libraries were mentioned by $15 \%$ of users, requesting immediate remedial action.

iv. $4 \%$ of users have requested extension of library opening hours during the examination period.

v. Few of the users prefer an extended loan period for library material. 
vi. Some respondents showed their concern over the provision of attached washrooms, arrangements for drinking water and refreshments in the close vicinity of the library. A respectful number of users appreciated the helpful library staff and their services.

\section{Conclusion}

This study proves the usefulness of investigating the level of users' satisfaction of the Open University of Sri Lanka designated for open distance learning. It provides an opportunity to understand the perceptions of distance learners about the library services provided by mini-scale libraries attached to regional learning centers.

Library users were satisfied with most of the facilities at the regional libraries: especially the physical environment including the arrangement of the collection, lighting, seating capacity, and cleanliness. The users were also satisfied with ancillary services such as the photocopy service, and opening hours. Users were comfortable with library rules and security measures at the library and also appreciate the positive attitudes of the library staff. However, it is important to note that users were not satisfied with the coverage and extent of the resource collection and limited computer facilities. The users have suggested the need for computerization of library services, a more up to date collection, and better Internet access within the library premises

As reported in previous literature, this study confirms that a library with an adequate collection and better physical facilities is more effective in satisfying its users. However, in a rapidly changing information age, a library should continuously improve its collection, services, and facilities in response to the changing needs of library users and periodically assess user perception through surveys or feed backs.

Further, it was found that users were not aware of some of the available resources and facilities (ex. VRC facility). Therefore, it is important to pay attention to designing more efficient awareness and publicity programs. 
In the light of the above findings, it can be concluded that, the administration should take steps to reinforce the services with which the users are satisfied, focus on services that need more improvement according to user concerns, and to take steps for resolution of identified problems to enhance users' satisfaction.

\section{References}

Ababio, K. A., Aidoo, E. N., Korankye, T., Saeed, B. I. I. \& Louis, M. (2012). Modeling student's satisfaction with library services in a tertiary institutions: evidence from Kumasi polytechnic, Information and Knowledge Management. 2(6), 85-94. Retrieved from https://pdfs.semanticscholar. org/d811/21fe0f447c8a2e82d426e3952ef31e2dcb0b.pdf

Kaushamalika, P. K. M., Arachchige, J. J. G. \& Weerakoon, W.R.W.M.A.U. (2018). Learner perception of library services at Kandy, Matara and Anuradhapura Regional Centers of the Open University of Sri Lanka. Journal of the University Librarians Association of Sri Lanka. 21(1), 64-80.

Larson, G. A., \& Owusu-Acheaw, M. (2012). Undergraduate students satisfaction with library services in a faculty library university of education, Winneba. Ghana. Library Philosophy and Practice (e-journal). Retrieved from http://digitalcommons.unl.edu/libphilprac/1027

Mairaj, M. L. \& Naseer, M. M. (2013). Library services and user satisfaction in developing countries: a case study. Health Information Libraries Journal, 30(4), 318-326. Retrieved from https://www.academia.edu/4177804/Library_services_and_user_satisfaction _in_developing_countries_a_case_study

Nawarathne, I.M., \& Singh, A. P. (2013). Users' satisfaction of the academic services in Sri Lanka, PEARL - A Journal of Library and Information Science. 7(2), 103-112. Retrieved from https://www.researchgate.net/ publication/272867244_Users'_Satisfaction_ofthe_Academic_Library_Servi ces_in_Sri_Lanka

Open University of Sri Lanka (2015), Open University Statistical Hand Book

Ryhana. R. (2010). Open University of Sri Lanka 1980-2010: from experiment to excellence. 
Veena, G. \& Kotari, P. N. (2016). User satisfaction with library resources, services, and facilities: A study in the SDM college library, Ujire, Indian journal of information sources and services, 6(1), 1-4. Retrieved from http://www.trp.org.in/wp-content/uploads/2016/10/IJISS-Vol.6-No.1-anuary -June-2016-pp.1-4.pdf

Vijeyaluxmy, S. (2015). Students' satisfaction with library services in an academic library: special reference to Trincomalee campus, 5th International Symposium, 2015, SEUSL. Retrieved from http://www.seu.ac.lk/res earchandpublications/symposium/5th/libraryandinformationscience/13.pdf 